\title{
Immunohistochemical Study of the Human
}

\section{Glomerular C3b Receptor in Normal Kidney and in Seventy-five Cases of Renal Diseases}

\author{
LOSS OF C3b RECEPTOR ANTIGEN IN FOCAL HYALINOSIS AND IN \\ PROLIFERATIVE NEPHRITIS OF SYSTEMIC LUPUS ERYTHEMATOSUS
}

\author{
Michel D. Kazatchine, Douglas T. Fearon, Marie Dominique Appay, \\ Chantal Mandet, and Jean Bariety, Institut National de la Santé et de la \\ Recherche Medicale U 28, Hopital Broussais, Paris, France; Departments of \\ Medicine, Harvard Medical School and the Division of Rheumatology and \\ Immunology, Brigham's and Women's Hospital, Boston, Massachussetts \\ 02115
}

\begin{abstract}
A в S T R A C T The presence and distribution of C3b receptors in normal human kidneys and in biopsies from 75 patients with renal disease were investigated by immunohistochemical techniques using monospecific rabbit antibody to the 205,000 -mol wt glycoprotein that is the $\mathrm{C} 3 \mathrm{~b}$ receptor of human peripheral blood cells. Anti-C3b receptor bound exclusively to podocytes in normal renal cortex, and was homogeneously distributed on the plasma membrane of these cells. Biosynthesis of the receptor by the podocyte was suggested by the presence of antigenic activity in the Golgi apparatus. Although occupancy of receptor sites following the interaction of kidney sections with aggregated IgG preincubated with normal serum inhibited binding to glomeruli of C3b coated cells, the C3b receptor remained accessible to anti-C3b receptor antibody. No staining of podocytes was found in extracapillary proliferating cells in rapidly progressive glomerulonephritis (GN). Segmental loss of staining was found in focal hyalinosis, nodular diabetic glomerulosclerosis, and amyloidosis while no detectable C3b receptor antigen was found in severe proliferative nephritis of systemic lupus erythematosus (SLE). Normal staining of podocytes was found in other nephropathies with endocapillary proliferation such as acute GN and mesangial GN and in renal diseases associated with immune deposits containing $\mathrm{C} 3$ such as mesangial proliferative and membranous SLE nephritis, idiopathic
\end{abstract}

Received for publication 14 August 1981 and in revised form 16 November 1981. membranous GN, membranoproliferative GN types I and II, mesangial GN with IgA or C3 deposition and Henoch Schönlein's purpura. Loss of C3b receptor antigen in the diffuse proliferative nephritis of SLE distinguishes it both from nonproliferative lupus nephritis and other immunologically mediated proliferative GN.

\section{INTRODUCTION}

Sheep erythrocytes and bacteria bearing C3b and C3bi, cleavage fragments of the third component of complement, adhered to glomeruli in frozen sections of human kidney (1-4). These particles were also found to adhere to the main body and trabecules of visceral epithelial cells (podocytes) from freshly prepared or cultured glomeruli $(5,6)$, indicating that at least the podocyte expressed receptor activity for fragments of C3. Decreased glomerular binding of particles bearing C3b and/or C3bi suggested depressed receptor activities in various renal diseases. Decreased receptor activities have been found to be independent of the site of C3 deposition (6), or correlated with mesangial (7) or parietal (8-11) deposits.

A glycoprotein of $205,000-\mathrm{mol} w \mathrm{t}(\mathrm{gp} \mathrm{205})^{1}$ was iso-

\footnotetext{
${ }^{1}$ Abbreviations used in this paper: AGN, acute glomerulonephritis; EAC4b3b, sheep erythrocytes coated with rabbit antibody and bearing $\mathrm{C} 3 \mathrm{~b}$, the major cleavage fragment of C3; FITC, fluorescein isothiocyanate conjugate; GBM, glomerular basement membrane; gp 205, 205,000-mol wt glycoprotein; LN, lipoid nephrosis; MGN, membranous glo-
} 


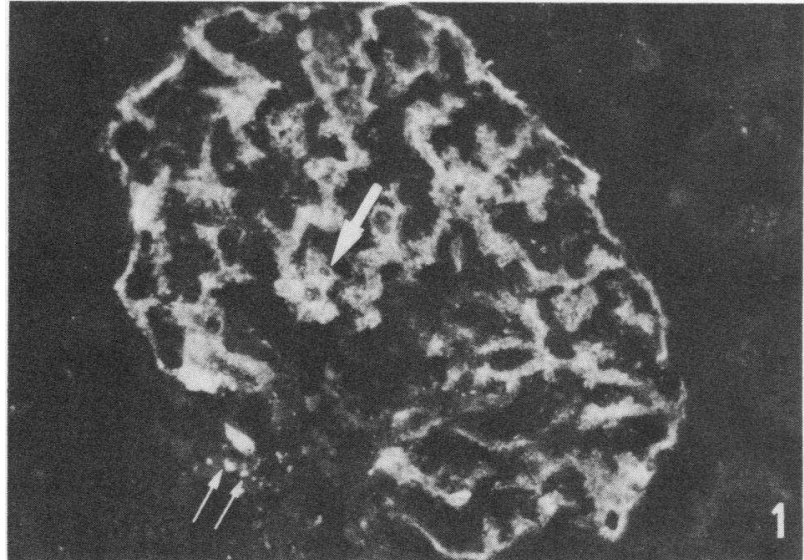

Figure 1 Photomicrograph $(\times 300)$ of a normal glomerulus stained for anti-C3b receptor antibody by indirect immunofluorescence. The podocytes are diffusely fluorescent. The areas of epithelial nuclei are negative (arrow). Parietal epithelial cells are negative, as are the mesangial stalks, and the extraglomerular mesangium. Spontaneously fluorescent lipof uschins (double arrow).

lated from human erythrocyte membranes (12) and identified as the $\mathrm{C} 3 \mathrm{~b}$ receptor of human erythrocytes, polymorphonuclear leukocytes, B lymphocytes, and peripheral blood monocytes. Monospecific antibody to gp 205 inhibited the capacity of these cells to bind C3b-coated sheep erythrocytes and immunoprecipitated a single membrane protein of $205,000 \mathrm{~mol} \mathrm{wt}$ from each cell type (13). This antibody to the C3b receptor had no inhibitory effect on the function of C3bi or C3d receptors $(13,14)$.

This study demonstrates the presence in human glomeruli of the $\mathrm{C} 3 \mathrm{~b}$ receptor antigen, which is exclusively localized to the podocyte. This specific marker for the plasma membrane of podocytes was assessed by immunofluorescence in 80 cases of renal diseases. Diffuse or segmental loss of antigenic activity was found in focal hyalinosis, in severe proliferative nephritis of systemic lupus erythematosus (SLE), in nodular diabetic glomerulosclerosis, and no antigenic activity was found in areas of extracapillary proliferation in rapidly progressive glomerulonephritis (RPGN).

\section{METHODS}

Kidney specimens. 80 renal biopsy specimens taken between 1978 and 1980 were selected from the files of the Hopital Broussais, Paris. Normal renal tissue was obtained

merulonephritis; MPGN, membranoproliferative glomerulonephritis; MSGN, mesangial glomerulonephritis; NHS, normal human serum; PBS, phosphate-buffered isotonic saline; RPGN, rapidly progressive glomerulonephritis; SLE, systemic lupus erythematosus. from two kidneys that could not be transplanted because of an abnormal vascular anatomy, and from normal parts of three nephrectomies performed for renal cell carcinoma.

Antibodies. C3b receptor was purified from membranes of human erythrocytes by sequential cation exchange chromatography, affinity chromatography on Sepharose-C3, gel filtration, and affinity chromatography on Sepharose-lentil lectin (12). Purified C3b receptor was homogeneous when analyzed by sodium dodecyl sulfate polyacrylamide gel electrophoresis with or without prior reduction of disulfide bonds. A rabbit was immunized with $75 \mu \mathrm{g}$ of $\mathrm{C} 3 \mathrm{~b}$ receptor protein emulsified in Freund's complete adjuvant and boosted 5 wk later by intramuscular injection of an additional 50 $\mu \mathrm{g}$ in incomplete Freund's adjuvant. Antiserum was obtained from the rabbit 2 wk after boosting; the IgG fraction was prepared by precipitation in $50 \%$ ammonium sulfate followed by chromatography on DE 52 cellulose.

Fluoresceinated sheep IgG anti-rabbit IgG (Institut Pasteur, Paris) was extensively absorbed with human IgG that had been insolubilized with glutaraldehyde. Fluorescein isothiocyanate (FITC)-conjugated anti-human IgG, anti-IgA, anti-IgM, anti-Clq and anti-C3 antisera were obtained from Behringwerke (Marburg, West Germany).

Aggregated IgG were obtained by DE 52 cellulose chromatography of normal human Cohn fraction II (U. S. Biochemical Corp., Cleveland, $\mathrm{OH}$ ) and heating of the IgG fraction at $63^{\circ} \mathrm{C}$ for $20 \mathrm{~min}$; the preparation was centrifuged at $1,500 \mathrm{~g}$ for $20 \mathrm{~min}$ at $4^{\circ} \mathrm{C}$; the supernatant was adjusted to a protein concentration (15) of $350 \mu \mathrm{g} / \mathrm{ml}$ in $0.15 \mathrm{M} \mathrm{NaCl}$ and stored at $-70^{\circ} \mathrm{C}$ until use.

Immunomorphological procedures. For routine optical microscopy, kidney biopsy specimens were fixed in Bouin's fixative and stained with Masson's trichrome, hematoxylineosin and periodic acid-methenamine silver. For immunofluorescent examination, frozen blocks were cut into $3-\mu \mathrm{m}$ sections in a Bright's cryostat (Instrument Company Ltd, Huntington, U. K.) Sections were fixed on slides and incubated with phosphate-buffered isotonic saline (PBS) for 30 $\mathrm{min}$ at room temperature before they were overlaid with the IgG fraction of anti-C3b receptor and the FITC anti-IgG, IgA, IgM, Clq, and C3. After incubation for $30 \mathrm{~min}$ at room temperature, the tissue sections were washed twice in PBS. The tissue sections incubated with anti-C3b receptor antibody were then overlaid with the absorbed FITC anti-rabbit IgG, incubated for $30 \mathrm{~min}$ at room temperature and washed twice with PBS. The slides were mounted under a cover slip and the tissue was examined by two investigators with a Leitz microscope (Leitz, Inc. Heerbrugg, Switzerland) using epiillumination and an FITC/50 filter. Controls for indirect immunofluorescence of anti-C3b receptor included biopsies incubated with nonimmune rabbit IgG or with rabbit IgG anti-bovine serum albumin. In some cases, serial sections of selected frozen biopsies were cut and the adjacent sections were stained with anti-C $3 b$ receptor antibody, hematoxylineosin and periodic acid-methenamine silver, respectively.

For immunoperoxidase staining and electron microscopic examination of $\mathrm{C} 3 \mathrm{~b}$ receptors, isolated glomeruli were prepared. Renal cortex from a freshly obtained normal kidney was gently disrupted and sequentially passed through an 80and a 115-mesh sieve. Glomeruli retained on the second sieve (16) were washed twice with $0.1 \mathrm{M}$ phosphate buffer $\mathrm{pH} 7.4$ and then fixed by incubation with $4 \%$ paraformaldehyde in this buffer. The fixed glomeruli were incubated with IgG anti-C3b receptor antibody for $5 \mathrm{~h}$ at room temperature, washed twice in the phosphate buffer and then incubated with peroxidase labeled $F\left(a b^{\prime}\right)_{2}$ sheep anti-rabbit IgG antibody (Institut Pasteur, Paris) for $5 \mathrm{~h}$ at $20^{\circ} \mathrm{C}$. After washing 


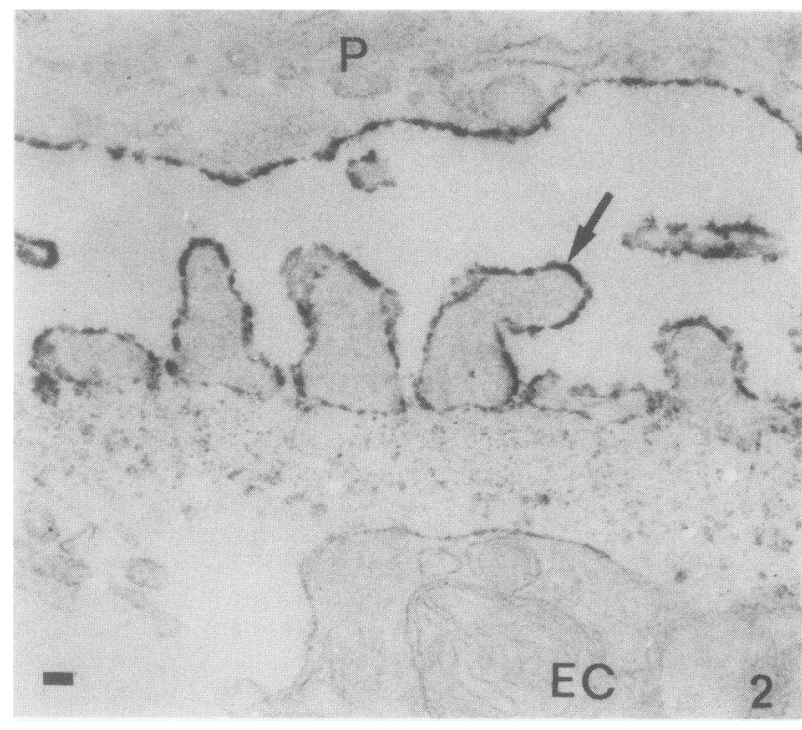

Figure 2 Electron micrograph $(\times 30,000)$ of glomerular capillary wall stained by immunoperoxidase for C $3 \mathrm{~b}$ receptor. All the cell surface of the pedicels (arrow) and main body of podocytes (P) are homogeneously labeled. No staining is seen in the areas of slit diaphragms. The surface of an endothelial cell (EC) is negative Bar: $0.1 \mu \mathrm{m}$.

for $36 \mathrm{~h}$ in the phosphate buffer, peroxidase activity was revealed by reaction with diaminobenzidine and $\mathrm{H}_{2} \mathrm{O}_{2}$ (17). Glomeruli were postfixed with osmium tetraoxyde, dehy- drated and included in epon (18). Ultrathin sections were cut using a Reichert OmU2 ultramicrotome (Reichert-Jung, Paris, France) and examined with a Zeiss EM9 or EM10 electron microscope (Carl Zeiss Inc., West Germany). Controls for endogenous peroxidase activity were sections treated as above with the exception of incubation with anti-C3b receptor antibody.

Binding of C3b-bearing cells to glomeruli. Sheep erythrocytes sensitized with rabbit antibody and bearing human C3b (EAC4b3b) were prepared as described (19). Two times $10^{7}$ EAC4b3b cells in $0.2 \mathrm{ml}$ of PBS were layered over 3$\mu \mathrm{m}$ frozen kidney sections and incubated in a moist chamber for $30 \mathrm{~min}$ at room temperature. The sections were then agitated in PBS to remove nonadherent cells, fixed with $2 \%$ glutaraldehyde in PBS and stained with hematoxylin and eosin. The number of cells bound to each of seven glomeruli was counted.

\section{RESULTS}

Normal kidney. Podocytes in all glomeruli observed in specimens from five normal kidneys stained with equal intensity with anti-C3b receptor antibody. The fluorescent pattern was homogeneous or very finely granular with negative areas corresponding to nuclei. Numerous indentations were seen, representing insinuations of podocytes between two adjacent capillary loops. Fluorescence abruptly stopped at the vascular pole of the glomerulus. The parietal epithelial cells of Bowman's capsule were negative, as were the extraglomerular mesangial region and all branches of

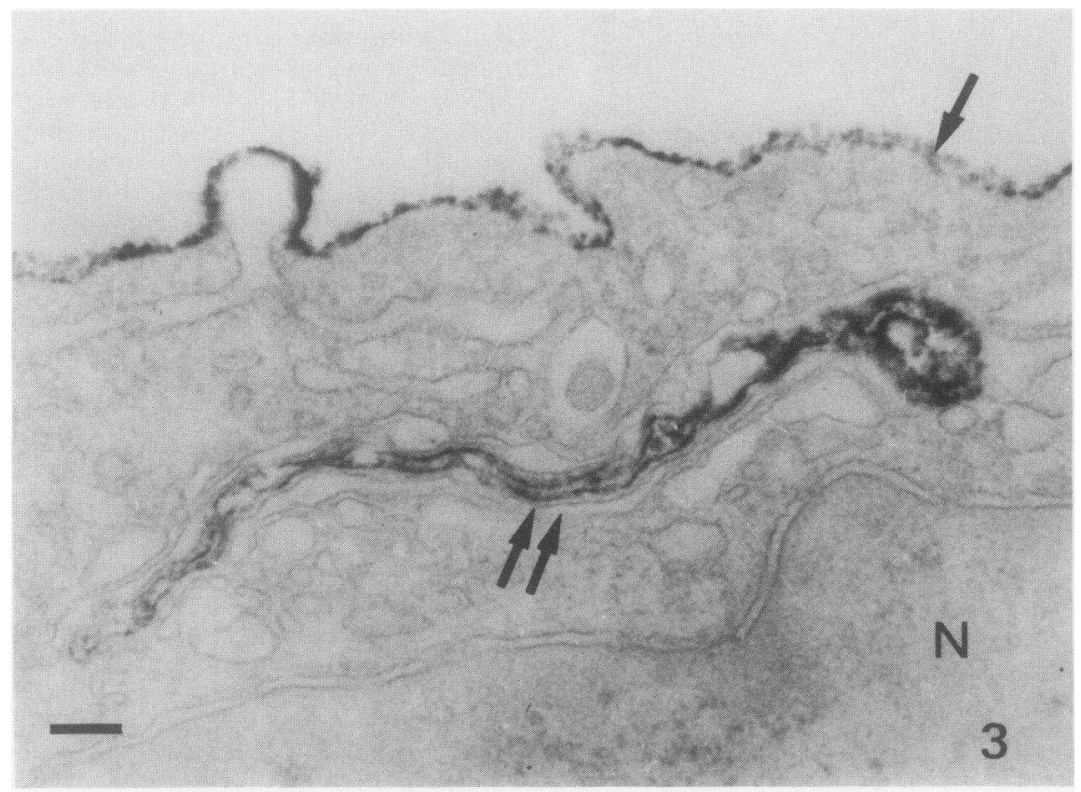

Figure 3 Electron micrograph $(\times 70,000)$ of the main body of a podocyte stained by immunoperoxidase for $\mathrm{C} 3 \mathrm{~b}$ receptor. The cell surface is homogeneously labeled (arrow) and part of the Golgi apparatus is also stained (double arrow). $\mathrm{N}$, nucleus. Bar: $0.1 \mu \mathrm{m}$. 

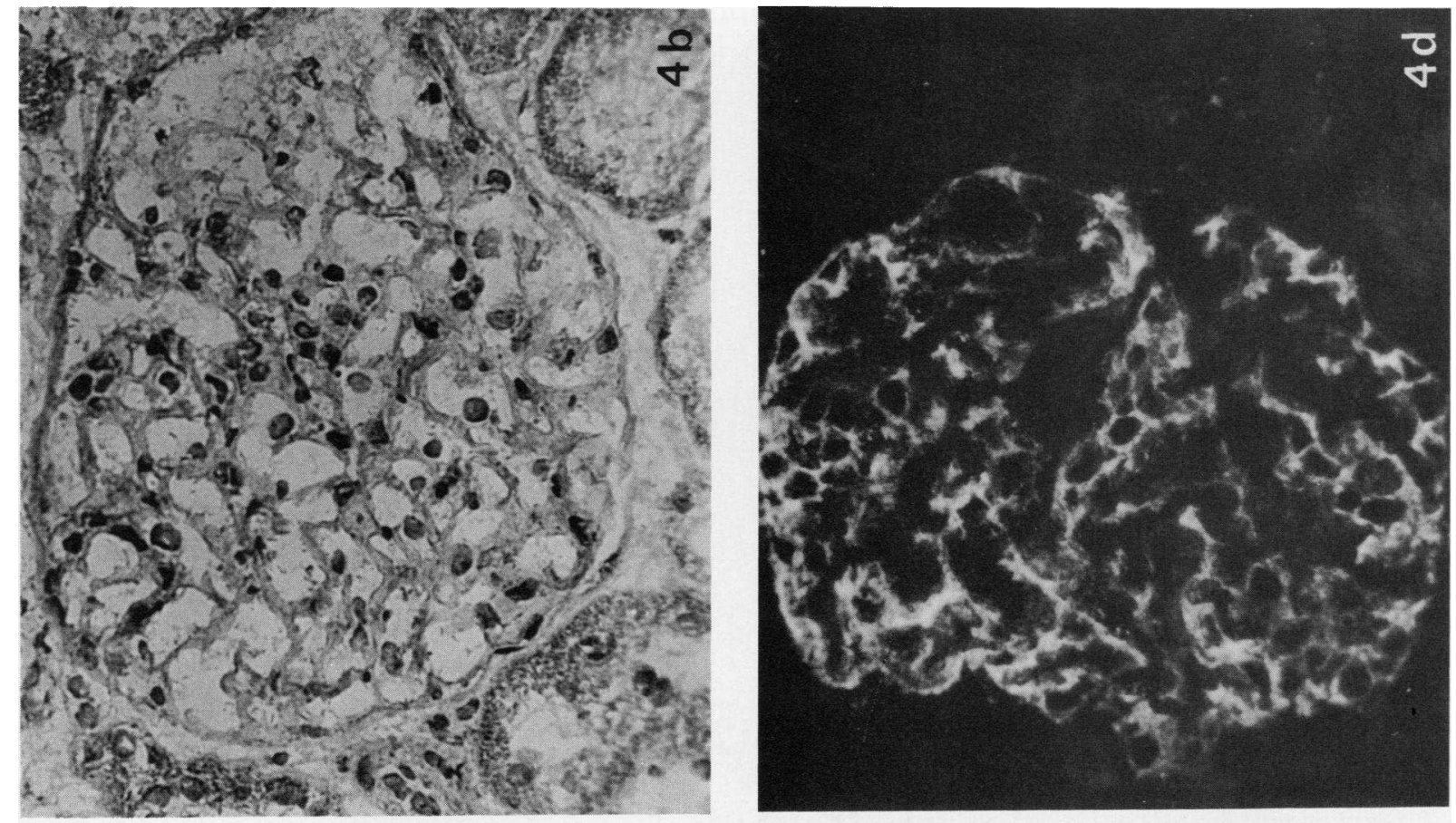

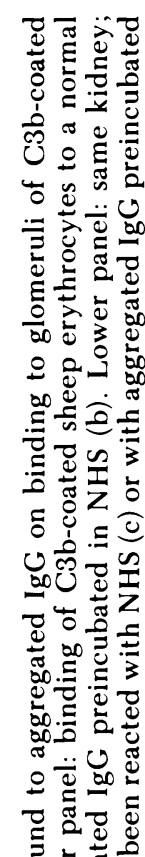
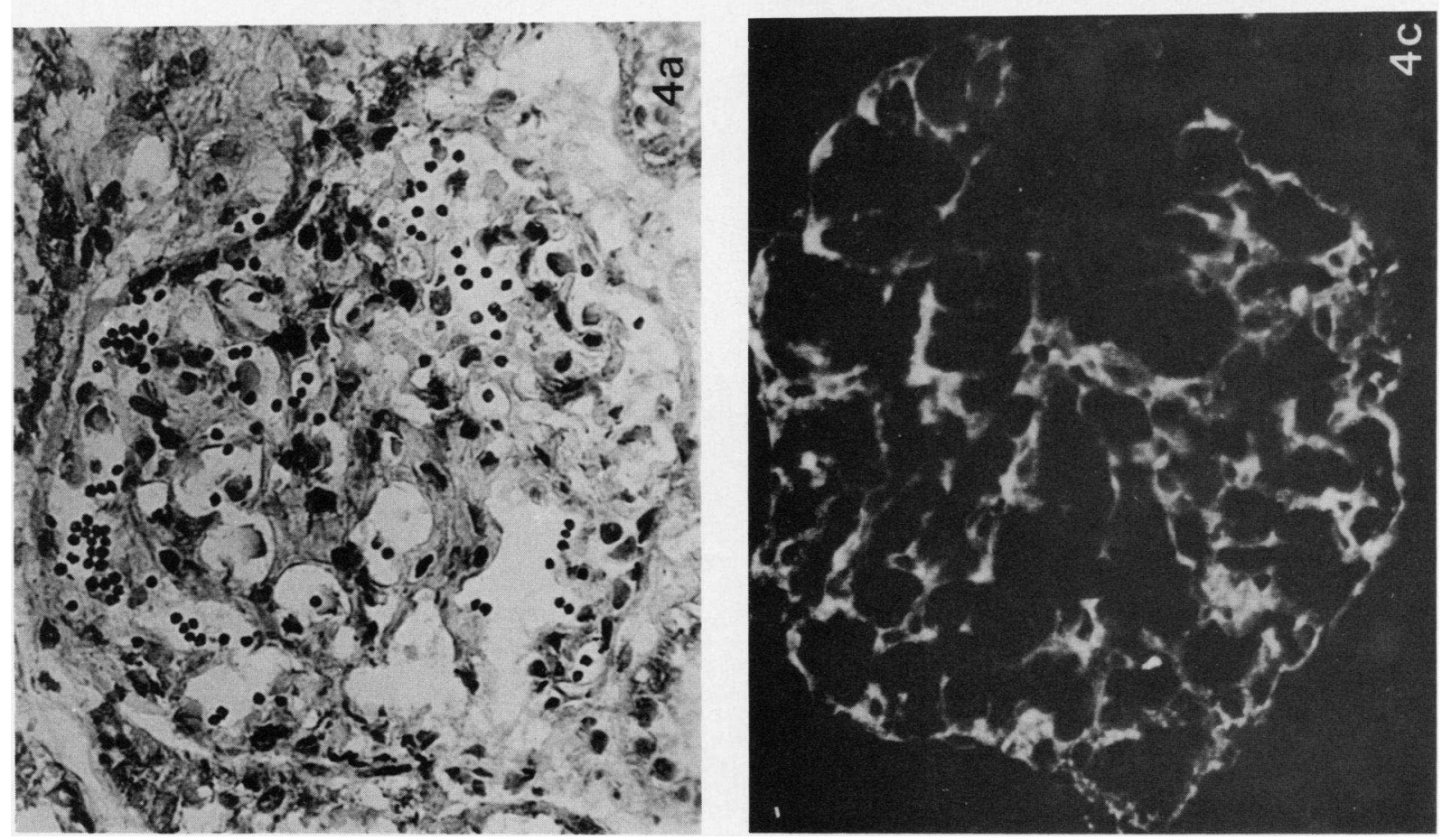

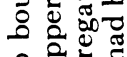

กิ

入े

\& 3

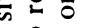

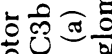

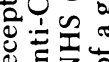

更

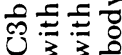

눙 월

रेंग्रें

육

प्ठ웡

$\div$ \$ के

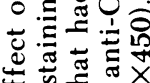

y

+ 을

些

氖气 至 
TABLE I

Pattern of Staining with Anti-C3b Receptor, Anti-C3, Anti-IgG, Anti-IgM, Anti-IgA, and Anti-Clq in 5 Normal and 75 Diseased Kidneys

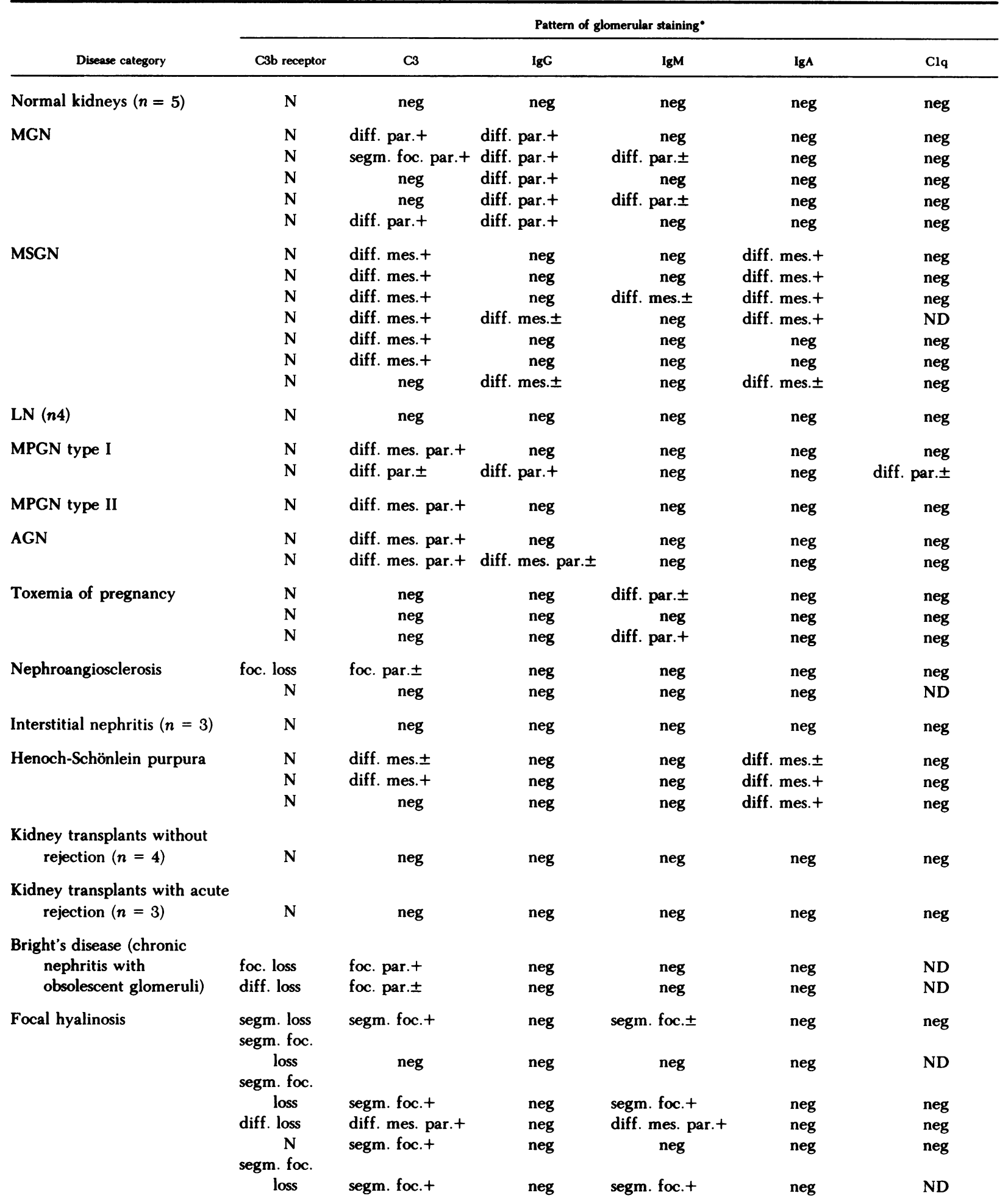


TABLE I (Continued)

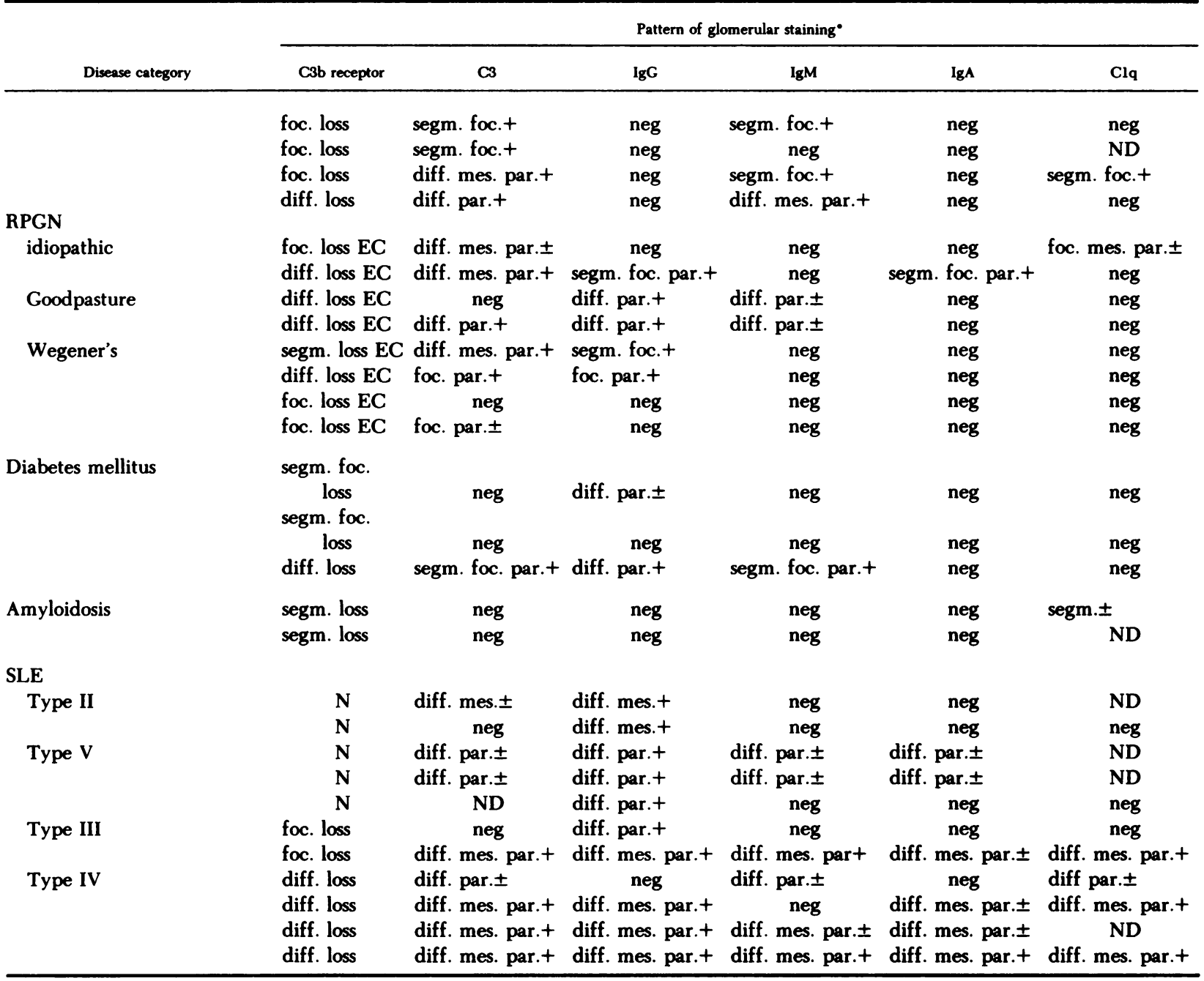

- N, pattern of staining similar to that of a normal glomerulus; neg, no staining; segm., segmental, e.g., affecting only part of the glomerulus; foc., focal, e.g., affecting only some glomeruli; diff., diffuse, e.g., affecting the entire or almost the entire glomerulus; mes., mesangial; par., parietal; ND, not done; EC, extracapillary. Intensity of staining was graded + or \pm .

intraglomerular mesangium. No capillary lumen was circled by circumferential staining (Fig. 1). Serial sections stained with methenamine-silver and with anti$\mathrm{C} 3 \mathrm{~b}$ receptor antibody demonstrated that fluorescence was continuous along the outer side of the glomerular basement membrane (GBM), with no fluorescence seen in the mesangial area. Indeed no other cell than the podocyte stained with anti-C $3 \mathrm{~b}$ receptor antibody in the renal cortex.

Using an indirect immunoperoxidase technique and electron microscopy, homogeneous granular staining was present on the surface of podocytes including the main body, trabecules, and pedicels (Fig. 2). Although less intense, C3b receptors were stained in the basement membrane-embedded part of the pedicels. The reaction product was seen within the Golgi apparatus of some podocytes but in no other intracellular location (Fig. 3). Thus the $\mathrm{C} 3 \mathrm{~b}$ receptor protein antigen is present on the plasma membrane of all podocytes in normal glomeruli in a homogeneous distribution and on no other cell type of the renal cortex.

To examine whether occupancy of receptor sites with $\mathrm{C} 3 \mathrm{~b}$ alters the binding of the antibody to the receptor on podocytes, normal kidney sections were layered with $100 \mu \mathrm{l}$ of fresh normal human serum (NHS) that had been incubated with $25 \mu \mathrm{g}$ of aggre- 


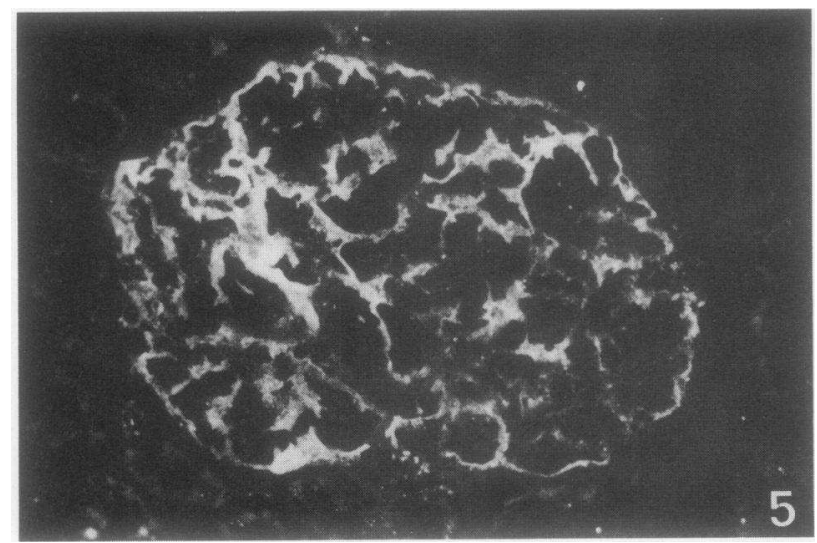

FIGURE 5 MGN. The pattern of staining of C3b receptors on podocytes is similar to that of a normal glomerulus $(\times 300)$. gated IgG for $15 \mathrm{~min}$ at $37^{\circ} \mathrm{C}$ or with NHS without aggregated IgG, in a moist chamber for $15 \mathrm{~min}$ at room temperature. The sections were then stained with antiC3b receptor antibody or assessed for their capacity to bind EAC4b3b cells. No difference in the staining of podocytes was seen whether the sections were preincubated with NHS containing aggregated IgG or with NHS alone; in contrast the mean number of EAC4b3b cells bound per glomerulus decreased from $100 \pm 20$ in the sections incubated with NHS to 2 in the sections incubated with NHS and aggregated IgG (Fig. 4). Thus saturation of the receptor with its natural ligand prevents further binding of cell-bound C3b but does not alter accessibility of the receptor molecule to the heterologous antireceptor antibody.

To examine whether binding of the antibody prevents binding of $\mathrm{C} 3 \mathrm{~b}$-coated cells to the $\mathrm{C} 3 \mathrm{~b}$ receptor
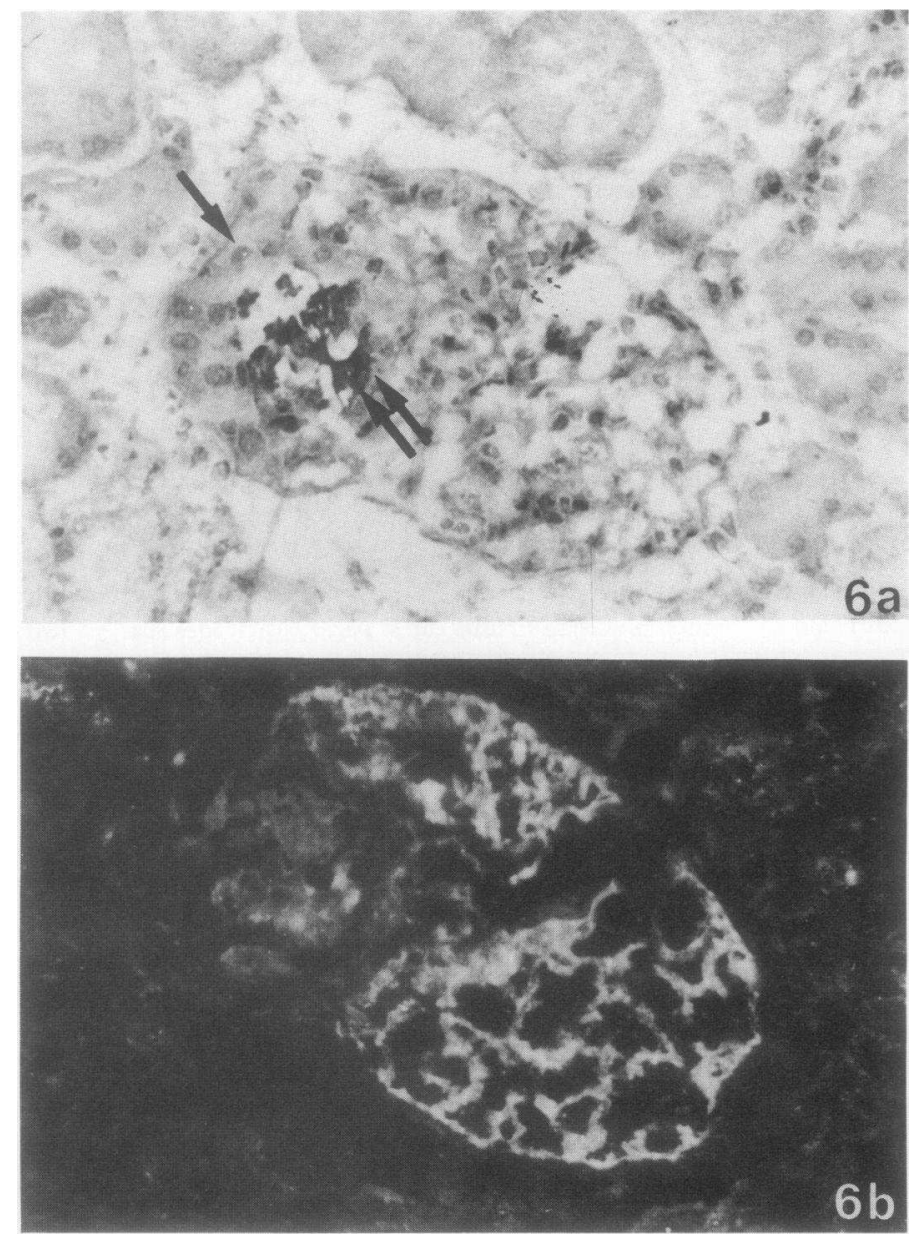

FIgURE 6 Wegener's granulomatosis. Adjacent sections stained with hematoxylin-eosin (a) and anti-C3b receptor antibody (b). The cells within the area of extracapillary proliferation (arrow), surrounding a necrotic lesion (double arrow), do not stain with anti-C3b receptor antibody. The residual part of the glomerulus demonstrates a normal pattern of staining with this antibody $(\times 300)$. 
on podocytes, normal kidney sections were incubated with $100 \mu$ l of undiluted anti-C3b receptor antiserum or with PBS for $15 \mathrm{~min}$ at room temperature in a moist chamber and then assessed for their capacity to bind EAC4b3b cells; no binding of the C3b bearing cells was observed in sections that had been preincubated with the antiserum while $100 \pm 20$ cells/glomerulus were bound in the control sections. Thus, binding of anti-gp 205 to the receptor inhibits access to the receptor of its natural ligand, as it does on peripheral blood cells (13).

Diseased kidneys. Biopsies from 75 individual patients with clinical, morphological, and immunohistochemical diagnoses listed in Table I were examined by indirect immunofluorescence for the presence of the C3b receptor. Normal pattern of staining of the $\mathrm{C} 3 \mathrm{~b}$ receptor on podocytes was seen in all biopsies from patients with minimal changes disease (lipoid nephrosis, LN). Normal pattern was also seen in patients with diseases in which parietal immune deposits occur such as idiopathic membranous nephropathy (MGN) (Fig. 5), membranoproliferative glomerulonephritis (MPGN) types I and II, acute glomerulonephritis (AGN) and with diseases in which mesangial immune deposition is present such as mesangial glomerulonephritis (MSGN) with IgA and/or C3 deposition and Henoch Schönlein's purpura. Thus among these diseases, no alteration in the pattern of C3b receptor staining was observed, irrespective of the presence or site of immune deposits including C3 deposition, or the presence of endocapillary proliferation (MPGN type I and type II, AGN, MSGN, Henoch Schönlein's purpura). The pattern of staining with anti-C3b receptor antibody was also normal in toxemia of pregnancy, transplanted kidneys with or without

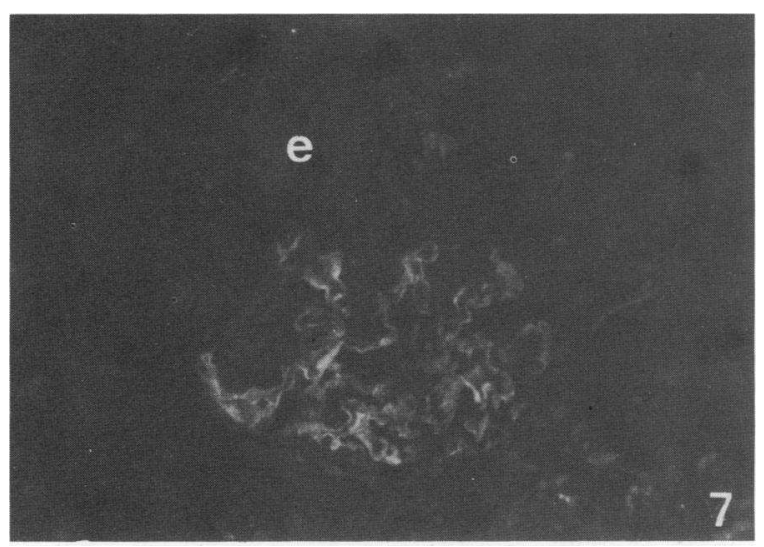

FIGURE 7 RPGN with anti-GBM antibodies and extracapillary proliferation. Anti-C3b receptor was revealed by antirabbit IgG antibody that cross-reacted with human IgG. All extracapillary cells (e) in the area of crescentic proliferation, where no GBM was stained, are negative $(\times 300)$.

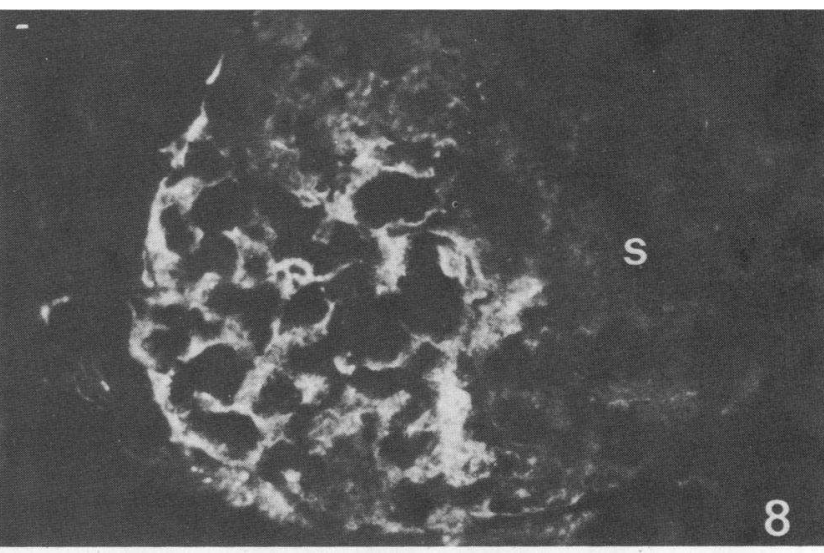

FIGURE 8 Focal hyalinosis. Staining with anti-C3b receptor antibody. In the part of the glomerulus corresponding to the segmental lesion (s), no staining of podocytes was seen, while these cells expressed $\mathrm{C} 3 \mathrm{~b}$ receptor antigen in the residual part of the glomerulus $(\times 400)$.

rejection, and in the extraglomerular diseases, interstitial nephritis and nephroangiosclerosis, except for obsolescent glomeruli. Infiltrating cells in transplant rejection and interstitial nephritis did not stain with anti-C3b receptor antibody.

Altered pattern of glomerular staining of $\mathrm{C} 3 \mathrm{~b}$ receptor were seen in biopsies from patients with idiopathic RPGN, in RPGN associated with Wegener's granulomatosis or with anti-GBM antibodies. No C3b receptor antigen was detected in glomeruli where extracapillary proliferation involved the whole urinary space. In a biopsy from a patient with Wegener's granulomatosis, the cells within the area of crescentic extracapillary proliferation surrounding a focal necrotic lesion had no detectable $\mathrm{C} 3 \mathrm{~b}$ receptor antigen, while the residual part of the glomerulus demonstrated normal pattern of staining of the podocytes (Fig. 6). In a biopsy from a patient with Goodpasture's syndrome and using as a revealing antiserum for indirect immunofluorescence a sheep anti-rabbit IgG that crossreacted with human IgG, staining of anti-GBM antibodies was observed. The area of crescentic proliferation outside the GBM was negative (Fig. 7). Thus the cells involved in extracapillary proliferation do not express the $\mathrm{C} 3 \mathrm{~b}$ receptor.

In focal hyalinosis, which is not characterized by extracapillary proliferation, altered patterns of $\mathrm{C} 3 \mathrm{~b}$ receptor staining were also observed; in the segmental lesions no staining of podocytes was seen, while in the residual areas of the glomeruli these cells expressed C3b receptor antigen (Fig. 8). Upon light microscopic examination, segmental lesions in focal hyalinosis include alteration and detachment of podocytes from the capillary wall, followed by their progressive disappearance $(20,21)$ (Fig. 9a). Examination of serial 

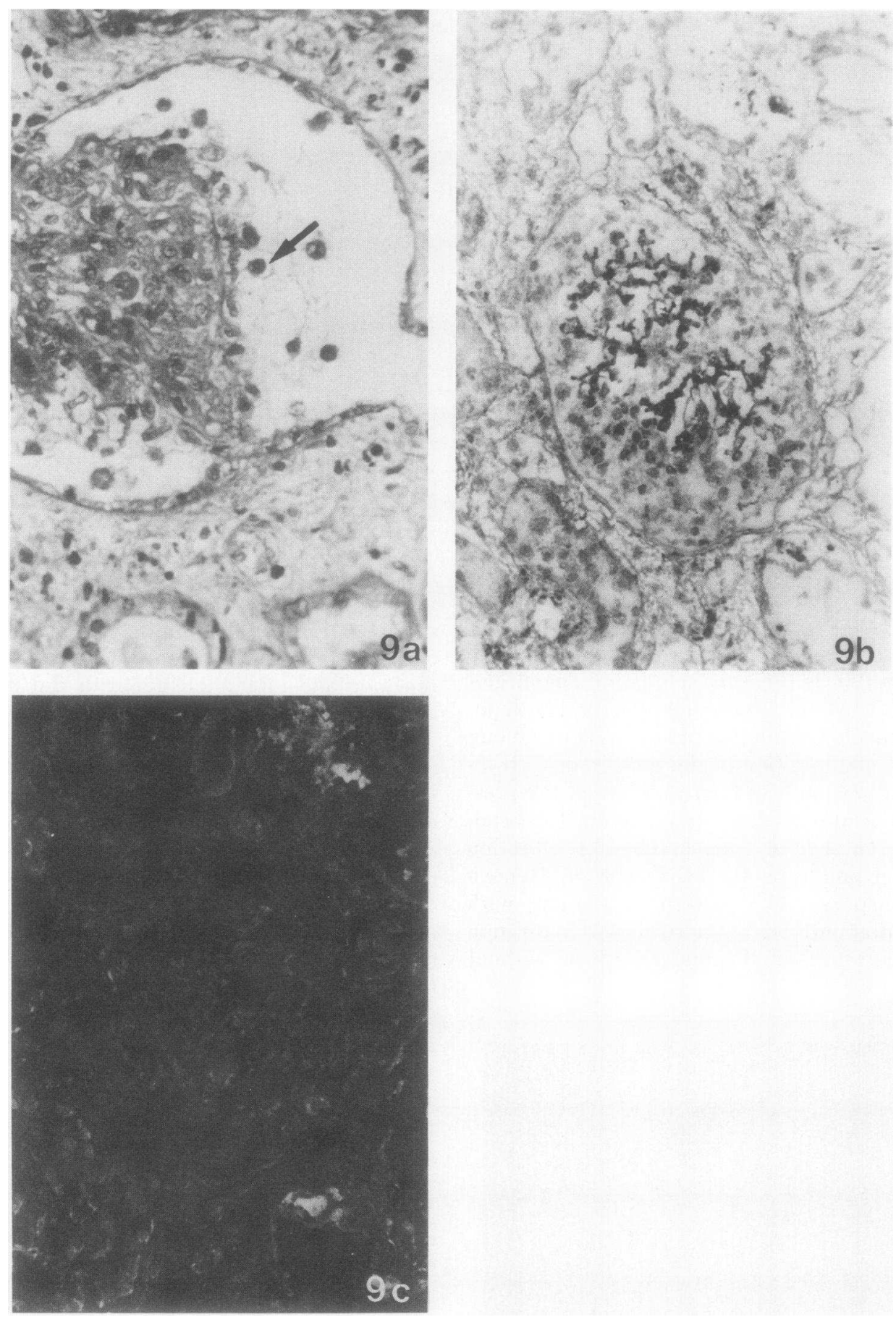

Figure 9 Diffuse hyalinosis. (a) A section stained with Masson's trichrome reveals that the glomerular tuft is retracted in the Bowman's space. There is progressive detachment of podocytes from the capillary wall (arrow) $(\times 400)$. (b)(c) Adjacent sections of a glomerulus from the same biopsy. The detached podocytes, which are seen in the section stained with hematoxylin-eosin (b), do not express C3b receptor antigen (c) $(\times 280)$.

sections of a biopsy from a patient with a form of the disease that involved almost all glomeruli, stained with Masson's trichrome and anti-C3b receptor, antibody revealed that the podocytes had entirely lost their ability to express $\mathrm{C} 3 \mathrm{~b}$ receptor antigen (Figs. $9 \mathrm{~b}$ and $\mathrm{c}$ ). Abnormal expression of the $\mathrm{C} 3 \mathrm{~b}$ receptor antigen 


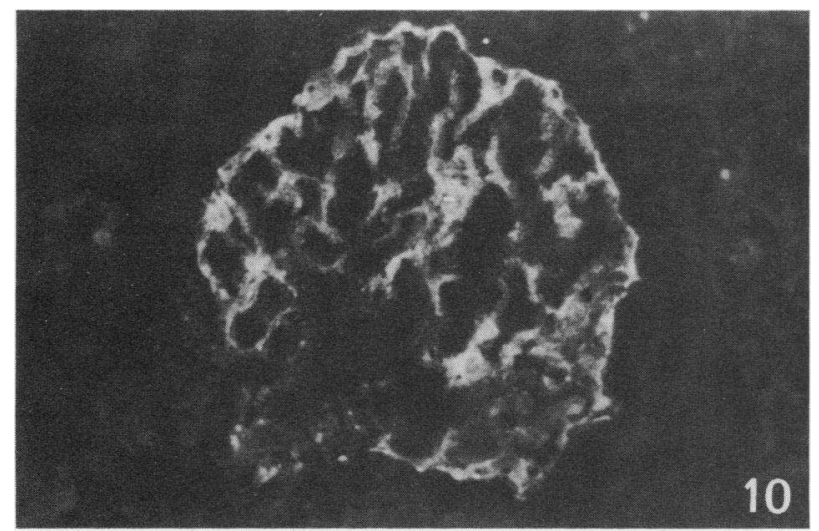

FIGURE 10 SLE nephritis type II: mild endocapillary proliferation and mesangial IgG deposits. Staining with anti$\mathrm{C} 3 \mathrm{~b}$ receptor antibody. The pattern of staining of $\mathrm{C} 3 \mathrm{~b}$ receptors on podocytes is similar to that of a normal glomerulus $(\times 300)$.

on podocytes was also observed in biopsies from patients with SLE, which was dependent on the histopathological type and severity of the disease. Biopsies obtained from 11 patients with SLE nephritis were examined, which included 3 patients with MGN and no cellular proliferation (type $\mathrm{V}$ according to the World Health Organization classification (22), 2 patients with slight mesangial proliferation and mesangial immune deposits (type II), 2 patients with mixed lesions of mild and severe proliferation in different glomeruli from the same biopsy (type III) and 4 patients with severe diffuse endocapillary proliferative nephritis (type IV). Biopsies from the nonproliferative types II (Fig. 10) and V exhibited normal patterns of
C3b receptor antigenic expression regardless of the presence of mesangial or parietal immune deposits. In biopsies from patients with type III nephritis, some glomeruli had normal patterns of staining of $\mathrm{C} 3 \mathrm{~b}$ receptor while others were partially or totally negative. All glomeruli examined in biopsies with type IV SLE nephritis had no detectable staining with anti-C3b receptor, although podocytes were seen upon light microscopic examination in glomeruli from the same patient and showing similar lesions (Figs. 1la and b). Thus loss of C $3 \mathrm{~b}$ receptor antigen on podocytes in SLE nephritis parallels the severity of endocapillary proliferation.

In two diseases where there is no renal deposition of C3, amyloidosis and the nodular form of diabetic glomerulosclerosis, areas adjacent to the amyloid deposits or the glomerulosclerotic nodules did not stain with anti-C3b receptor antibody. In contrast, podocytes in biopsies from patients with moderate diffuse diabetic glomerulosclerosis expressed C3b receptor antigen in a normal distribution.

\section{DISCUSSION}

Antibody to the C3b receptor of human erythrocytes $(12,13)$, which also recognizes the receptor on human polymorphonuclear leucocytes, B lymphocytes, and monocytes, bound to the podocytes in glomeruli from normal human renal cortex (Figs. 1, 2, and 3). C3b receptor activity had been recognized on these cells in previous studies $(1,5,6)$ by the adherence of C3bcoated particles. Immunohistochemical techniques utilizing anti-C3b receptor antibody demonstrated the $\mathrm{C} 3 \mathrm{~b}$ receptor antigen to be present on podocytes and
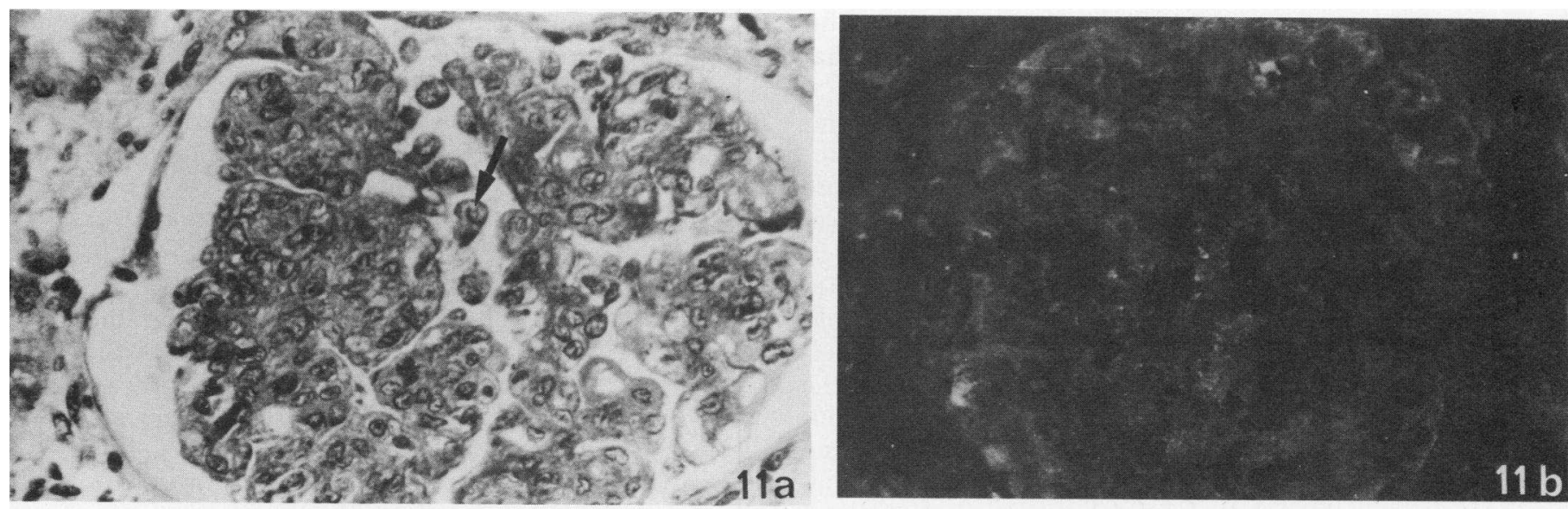

FIGURE 11 SLE nephritis type IV: severe diffuse endocapillary proliferation; diffuse mesangial and parietal deposits of C3, IgG, IgM, and IgA $(\times 450)$ (a) A section stained with Masson's trichrome demonstrates the diffuse endocapillary cell proliferation and the presence of altered podocytes (arrow). (b) A frozen section of a glomerulus from the same biopsy stained with antiC3b receptor antibody. No immunofluorescence is seen. 
on no other cell type in the renal cortex (Fig. 1). Ultrastructural examination showed the antigen to be homogeneously distributed on the plasma membrane of the main body, trabecules, and pedicels of the podocyte (Fig. 2). The receptor was present even in areas where the pedicels are embedded in the lamina rara externa; occasional decrease in staining in these areas might represent either impaired penetration of the antibody or diminished number of receptors (Fig. 2). Synthesis of the receptor molecule by podocytes was suggested by the presence of the antigen within the Golgi apparatus (Fig. 3). Thus the $\mathrm{C} 3 \mathrm{~b}$ receptor activity that had been recognized in human glomeruli represents a membrane protein of the podocyte that is antigenically related to the gp 205 receptor of peripheral blood cells.

Crescentic areas of extracapillary proliferation whether segmental or diffuse, did not stain with antiC3b receptor antibody suggesting that these cells are not podocytes (Figs. 6 and 7). There is some question about the origin of the proliferating cells; they are thought to be parietal epithelial cells (23), but have also been considered to be derived from podocytes (24), or from bone marrow-derived monocytic cells (25). The inability to detect the $\mathrm{C} 3 \mathrm{~b}$ receptor, which is a normal constituent of the peripheral blood monocyte $(4,13,26)$, does not allow to differentiate whether the cells in crescentic areas are of monocytic or parietal epithelial cells origin, since mononuclear cells infiltrating the interstitium in biopsies of patients with acute transplant rejection or interstitial nephritis did not stain for C3b receptor. The absence of staining of infiltrating cells, although peripheral blood monocytes stain in suspension, may be due to loss of receptor or, more likely, to the low density of receptors on monocytes as compared with podocytes, as suggested by immunoelectron microscopy and by comparing the staining of podocytes in normal glomeruli (Fig. 1) with that of peripheral blood cells in suspension $(27,28)$.

Altered patterns of staining for this specific membrane marker of the podocyte was found in the unrelated diseases: focal hyalinosis (Figs. 8 and 9), diffuse proliferative SLE nephritis (Fig. 11), the nodular form of diabetic glomerulosclerosis, and amyloidosis. In both nodular diabetic glomerulosclerosis and amyloidosis, decreased staining with anti-C3b receptor could in part be related to the loss of podocytes in the acellular areas. However, podocytes are present in the perinodular capillaries of the diabetic nodular lesions and have been noted to appear enlarged and detaching from the capillary wall (29). In focal hyalinosis, podocytes in the areas of focal lesions and throughout the glomerulus in diffuse hyalinosis where there is no staining for $\mathrm{C} 3 \mathrm{~b}$ receptor, are also enlarged, vacuolated and in the process of detaching from the GBM (Fig. 9a) (20). Thus the loss of detectable C3b receptor antigen could not have been secondary only to the loss of podocytes but may reflect a metabolic abnormality of the podocyte, which has impaired biosynthesis of this membrane protein. However in another example of altered podocyte function, LN in which there is dedifferentiation of the foot processes accompanied by histochemical alterations of the podocyte's cell coat (30), a normal distribution of the $\mathrm{C} 3 \mathrm{~b}$ receptor antigen was found.

As the C3b receptor has been shown on polymorphonuclear leukocytes to be capable of mediating adsorptive endocytosis of ligand (27) leading to clearance of the receptor from the plasma membrane, it was important to consider, as has been suggested in previous studies of the C3b receptor in immune nephropathies (7-11), whether undectable receptor content of podocyte in SLE nephritis type IV could be related to a similar interaction. However, decreased receptor antigen could not be correlated simply to the presence of immune deposits containing $\mathrm{C} 3$ since reaction of glomeruli with NHS that had been preincubated with aggregated IgG did not alter the staining of podocytes with anti-C3b receptor antibody (Fig. 4), and since normal immunofluorescence patterns with anti-C3b receptor antibody were observed in glomeruli from patients with SLE nephritis type II (Fig. 10) and type V, idiopathic MGN (Fig. 5), MPGN type I and II, AGN, MGSN with IgA or C3 deposition, and HenochSchönlein's purpura in which both C3 and/or immunoglobulin deposits are found in parietal (subendothelial, intramembranous, or subepithelial) or mesangial location (Table I). Moreover, C3 deposits were not a constant feature of focal hyalinosis (Table I). Among the different types of SLE nephritis there was an association between the loss of $\mathrm{C} 3 \mathrm{~b}$ receptor antigen (Figs. 6, 10, and 11) and the severity of endocapillary proliferation which has been suggested to be predictive of a poor renal prognosis (31). In the nonproliferative types II and V, C3b receptor antigen staining was normal; in biopsies with type IV SLE nephritis, there was no detectable $\mathrm{C} 3 \mathrm{~b}$ receptor antigen although podocytes could be seen in glomeruli showing similar lesions; in biopsies with type III, the pattern of staining with anti-C3b receptor was inversely related to the extent of proliferative changes. This apparent correlation between loss of receptor antigen and endocapillary proliferation however was not found in other endocapillary proliferative diseases such as AGN, MPGN, or MSGN. Therefore the proliferative nephritis of lupus has specific abnormality of the podo- 
cyte, loss of $\mathrm{C} 3 \mathrm{~b}$ receptor antigen, which distinguishes it both from nonproliferative lupus nephritis and other immunologically mediated proliferative glomerulonephritis.

In the present study, loss of $\mathrm{C} 3 \mathrm{~b}$ receptor antigen among nephropathies thought to be of immune origin, was restricted to focal hyalinosis and severe proliferative nephritis of SLE. This finding is in apparent contrast to earlier reports of receptor function that found decreased binding of C3b-coated particles to glomeruli in most immune nephropathies. However, adherence reactions could not differentiate between receptor loss and receptor occupancy by $\mathrm{C} 3 \mathrm{~b}$ in immune deposits; since receptor sites occupied by their natural ligand remained accessible to anti-receptor antibody (Fig. 4), the absence of immunofluorescence with anti-C3b receptor indicates the deletion of this membrane protein from the podocyte. The latter abnormality suggests that in focal hyalinosis and severe proliferative nephritis of SLE, there is an alteration in the biosynthesis or turnover of the receptor by the podocyte that is not a feature of other renal diseases.

\section{ACKNOWLEDGMENTS}

The expert secretarial assistance of Miss Fredericka de Valicourt is gratefully acknowledged.

This investigation was supported by grants CRL 815036 from Institut National de la Santé et de la Recherche Medicale (France) and 80-7-0215 from the Delegation Generale à la Recherche Scientifique et Technique, France, and in part by grants AI-07722, AI-10356, AI-17917, and RR-05669 from the National Institutes of Health.

\section{REFERENCES}

1. Gelfand, M. C., M. M. Frank, and I. Green. 1975. A receptor for the third component of complement in the human renal glomerulus. J. Exp. Med. 142: 1029-1034.

2. Matre, R., and O. Tonder. 1976. Complement receptors in human renal glomeruli. Scand. J. Immunol. 5: 437441.

3. Carlo, J. R., R. B. Nagle, and M. L. Shin. 1978. The nature of the receptor for complement $(\mathrm{C} 3 \mathrm{~b})$ in the human renal glomerulus. Am. J. Clin. Pathol. 69: 486-493.

4. Carlo, J. R., S. Ruddy, E. J. Studer, and D. H. Conrad. 1979. Complement receptor binding of C3b-coated cells treated with C3b inactivator, $\beta-1 \mathrm{H}$ globulin, and trypsin. J. Immunol. 123: 523-528.

5. Shin, M. L., M. C. Gelfand, R. B. Nagle, J. R. Carlo, I. Green, and M. M. Frank. 1977. Localization of receptors for activated complement on visceral epithelial cells of the human renal glomerulus. J. Immunol. 118: 869-873.

6. Burkholder, P. M., T. D. Oberley, T. A. Barber, A. Beacom, and C. Koehler. 1977. Immune adherence in renal glomeruli. Complement receptor sites on glomerular capillary epithelial cells. Am. J. Pathol. 86: 635-651.
7. Sobel, A. T., Y. E. Gabay, and G. Lagrue. 1976. Analysis of glomerular complement receptors in various types of glomerulonephritis. Clin. Immunol. Immunopathol. 6: 94-101.

8. Gelfand, M. C., M. L. Shin, R. B. Nagle, I. Green, and M. M. Frank. 1976. The glomerular complement receptor in immunologically mediated renal glomerular injury. N. Engl. J. Med. 295: 10-14.

9. Moran, J. E., G. Colasanti, N. Amos, and D. K. Peters. 1977. C3b receptors in glomerular disease. Clin. Exp. Immunol. 28: 212-217.

10. Petterson, E. E., A. K. Bhan, E. E. Schneeberger, A. B. Collins, R. B. Colvin, and R. T. McCluskey. 1978. Glomerular C3 receptors in human renal disease. Kidney Int. 13: 245-252.

11. Matre, R., B. M. Iversen, S. Thunold, and O. Tonder. 1978. Complement receptor in pathological human renal glomeruli. Scand. J. Immunol. 7: 399-404.

12. Fearon, D. T. 1979. Regulation of the amplification C3 convertase of human complement by an inhibitory protein isolated from human erythrocyte membrane. Proc. Natl. Acad. Sci. U. S. A. 76: 5867-5871.

13. Fearon, D. T. 1980. Identification of the membrane glycoprotein that is the $\mathrm{C} 3 \mathrm{~b}$ receptor of the human erythrocyte, polymorphonuclear leukocyte, B lymphocyte, and monocyte. J. Exp. Med. 152: 20-30.

14. Dobson, N. J., J. D. Lambris, and G. D. Ross. 1981. Characteristics of isolated erythrocyte complement receptor type one $\left(\mathrm{CR}_{1}, \mathrm{C} 4 \mathrm{~b}-\mathrm{C} 3 \mathrm{~b}\right.$ receptor), and $\mathrm{CR}_{1}$-specific antibodies. J. Immunol. 126: 693-698.

15. Lowry, O. H., N. J. Rosebrough, A. L. Farr, and R. J Randall. 1951. Protein measurement with the Folin phenol reagent. J. Biol. Chem. 193: 265-275.

16. Kurokawa, K., F. J. Silverblatt, K. L. Klein, M. S. Wang, and R. L. Lerner. 1979. Binding of ${ }^{125}$ I-insulin to the isolated glomeruli of rat kidney. J. Clin. Invest. 64: 1357-1364.

17. Graham, R. C., J. Vand, and M. J. Karnovsky, 1966. The early stages of absorption of injected horseradish peroxidase in the proximal tubules of mouse kidney: ultrastructural cytochemistry by a new technique. J. Histochem. Cytochem. 14: 291-302.

18. Bariety, J., P. Druet, F. Laliberte, C. Sapin, M. F. Belair, and $M$. Paing. 1978. Ultrastructural evidence, by immunoperoxidase technique, for a tubular reabsorption of endogenous albumin in normal rat. Lab. Invest. 38: 175-180.

19. Fearon, D. T., K. F. Austen, and S. Ruddy. Formation of a hemolytically active cellular intermediate by the interaction between properdin factors $B$ and $D$ and the activated third component of complement. J. Exp. Med. 138: 1305-1313.

20. Grisham, E., and J. Churg. 1975. Focal glomerular sclerosis in nephrotic patients: an electron microscopic study of glomerular podocytes. Kidney Int. 7: 111-122.

21. Habib, R. 1973. Focal glomerular sclerosis. Kidney Int. 4: $355-361$.

22. McCluskey, R. T. 1975. Lupus nephritis. In Kidney Pathology Decennial 1966-1975. S. C. Sommers, editor. Appleton-Century-Crofts, New York. 435.

23. Morita, T., Y. Suziki, and J. Churg. 1973. Structure and development of the glomerular crescent. Am. J. Pathol. 72: 349-357. 
24. Heptinstall, R. H. 1974. Pathology of the Kidney. Little, Brown \& Company, Boston. 2nd edition. 371-391.

25. Atkins, R. C., S. R. Holdsworth, E. F. Glasgow, and F. E. Matthews. 1976. The macrophage in human rapidly progressive nephritis. Lancet. I: 830-832.

26. Huber, R., M. J. Polley, W. D., Lindscott, H. H. Fudenberg, and H. J. Müller Eberhard. 1968. Human monocytes. Distinct receptor sites for the third component of complement and for immunoglobulin G. Science (Wash. D. C.). 162: 1281-1283.

27. Fearon, D. T., I. Kaneko, and G. Thomson. 1981. Membrane distribution and adsorptive endocytosis by C3b receptors on human polymorphonuclear leukocytes. $J$. Exp. Med. 154: 1615-1628.

28. Petty, H. R., L. M. Smith, D. T. Fearon, and H. M. McConnell. 1980. Lateral distribution and diffusion of the $\mathrm{C} 3 \mathrm{~b}$ receptor of complement, HLA antigens, and lipid probes in peripheral blood leukocytes. Proc. Natl. Acad. Sci. U. S. A. 77: 6587-6591.

29. Cohen, A. H., F. Mampaso, and L. Zamboni. 1977. Glomerular podocyte degeneration in human renal disease. An ultrastructural study. Lab. Invest. 37: 30-42.

30. Hirsch, H. Z., S. K. Ainsworth, S. S. Spicer, E. H. Kurtz, and R. M. Brissie. 1981. Ultrastructural assessment by colloidal iron of the distribution and localization of anionic sites in human glomerulonephritides. Am. J. Path. 102: 99-107.

31. Baldwin, D. S., M. C. Gluck, J. Lowenstein, and G. R. Gallo. 1977. Lupus nephritis. Clinical course as related to morphologic forms and their transitions. Am. J. Med. 62: $12-30$. 